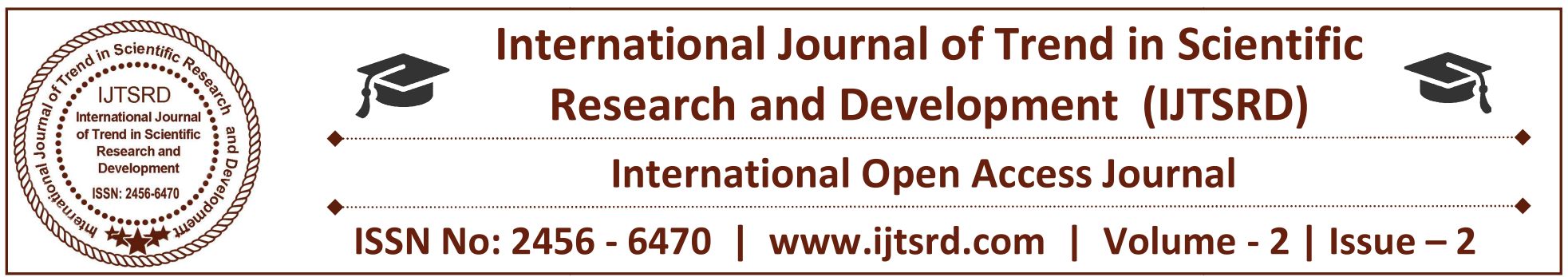

\title{
Conceptualising Educational Disparity in the Provision of Health Care Services in Cuba and Cameroon: Implications To Educational Administrators
}

\author{
Michael N. Agbor Ph.D \\ HTTTC Kumba, University of Buea, Cameroon
}

\section{ABSTRACT}

This paper focused on the Educational Planning (recruitment, training and retention) strategies used by Cuba to produce best medical doctors in the world despite the fact she is a developing and poor nation. It traces the historical aspect of both Cuba and Cameroon and proceeds with causal comparative analysis taking cognizance of the contextual challenges. (socio-cultural, political renand economic). The strategies used by Cuban Educational Administrators in reorganising such a model system of education revealed the gaps which Cameroon needs to draw inferences from. This paper also delves into reasons why Cameroon, another third world country cannot be matched with Cuba despite an abundance of resources. The educational systems of both countries are analysed and technical strategies sought. The study draws lessons from Cuba's educational system and strategies employed to improve on her training of medical practitioners. It poses the question: what has Cuba used with less than what miracle has used to produce quality medical personnel with less resource? Why can Cameroon not use her abundant natural resources and educational system to produce same number of quality and quantity of medical of medical doctors? Past and current documents have been consulted and they have been properly scrutinized to come out with the reasons why Cuba offers high quality manpower (medical personnel) the best health care services and strategies employed to produce this as well as the reasons why Cameroon cannot even produce a self-sufficient number of medical personnel though a third world country like Cuba. The study also recommends some educational strategies that Cameroon can adopt to improve on quality and quantity of medical practitioners in the country.

Keywords: third world countries, recruitment, training, retention, medical personnel, education strategy, health care services

\section{Introduction}

The growing body of international research on educational quality and effectiveness, while continuing to evolve in many ways, has developed broad agreement on many of the factors associated with high school quality and effectiveness. Much of this consensus was developed at the World Conference on Education for All (Jomtien, Thailand, 1990) and subsequently elaborated. These factors range from systemic factors such as a sufficiency of facilities and resources, supportive policy environment, and parent and community involvement in schools, to school-based factors such as high expectations, clear goals, creative use of high-quality instructional materials, employment of motivated teachers, on-going professional development, comprehensive assessment and feedback, and teacher and student involvement in defining, carrying out, and evaluating learning processes and outcomes. Interestingly, the Cuban education system adopted many of these features independently of the school effectiveness and quality research. This paper discusses those features as well as on-going tensions 
facing the system. The National System of Education in Cuba is conceived as an articulate group of educational levels and types of schools. The primary level contains early childhood education, primary, secondary (general and professional), Adult education and special education for handicap children. The secondary level contains the junior and senior high schools and the medium level Technical and Professional centres. In the tertiary level, the different types of university institutions are grouped. This structure is present along the Island, allowing the flow and the students in a continuous articulation from some levels to others in the different provinces and municipalities. Systemic operations of educational sectors and the relationships with the different ministries and social organizations, explains for the higher results achieved in health and educational matters.

Four ministries implement the education policy in Cameroon: namely the ministry of Basic education, the ministry of secondary education, the ministry of higher education and the ministry of employment and vocational education. Over the past two decades, Cameroon's primary and secondary education systems provided significant improvements in educational opportunities for children and youth. Nearly 3.4 million children enrolled in primary education in 2009, up from just under 2 million in 1991. More than $90 \%$ of school-age children enrolled in primary school in 2009 , compared to only $69 \%$ in 1991. The abolition of school fees in primary education in 2000 spurred some of this increase in total enrolment. Total secondary enrolment more than doubled in the past two decades, reaching nearly 1.3 million total students in 2009. Overall, children spend 2.5 more years in school than two decades ago, totalling an average 10 years of education, well into secondary school. Government distribution of civil servants and contract teachers does not benefit schools with the greatest needs. Despite recent government policies aimed to improve teacher employment conditions and motivation as well as reduce favouritism and nepotism - central decisions on how to allocate teachers across regions remains partly arbitrary and mired in political intervention. Nearly one-third (35\%) of primary school teacher appointments are unrelated to total enrolment. Regions with the greatest needs are not those desired by teachers, who frequently request (and are often granted transfers). The comparativeness of this study indicate lapses which Cameroon educational systems need to reinforce as a measure to meet up with her Cuban counterpart.

In conceptualising the Cuban educational system, it is imperative to revisit Cuban educational policies in terms of financing, planning and implementation. The relationship between a good and flexible educational system and a productive healthcare system is undisputed. The Cuban State assigns important resources to the financing of the social services, occupying a prominent place the current expenditure in education inside the State budget. The current expenditure in education in relation with the total current expenditure of the national budget is of 22 per cent and with relationship to the total expenditure of the budget, it reaches 14 per cent. The current expenditure of education as a percentage of the GDP in the whole period beginning in 1990 has never been inferior to 6 per cent. With the gradual improvement of the economy after 1993, a consistent increase of the current expenditure in education is observed and as a percentage of the GDP, it reaches $9,3 \%$ in the year 2002.

In the colonial era, in which western imperialist nations extended their colonial tentacles to the third world countries, the training of medical personnel in these third world countries was the responsibility of the western European imperialist. At the dawn of independence, these imperialist nations did not only withdraw political responsibilities over the third world countries but also withdrew every aspect of their technology including the training of medical personnel. The developing countries including Cuba and Cameroon thus assumed the responsibility of training their own medical personnel in varying degrees depending on the available resources and these greatly improved health care services in Cuba than in Cameroon.

\section{The purpose of the study}

This paper ascertains the educational strategies put in place by a poor country (Cuba) to achieve such a high degree of success in the training of medical practitioners providing one of the best health care services in world. This paper also intends to verify the reasons why Cameroon cannot train enough medical practitioners for use in the country, even though a third world countries as well as some measures that can enable the nation advance in this sector.

The objectives of this study therefore are to: 
International Journal of Trend in Scientific Research and Development (IJTSRD) ISSN: 2456-6470

1. Bring out the reasons why Cuba as a third world country renders the best health care services.

2. Examine the educational strategies put in place by the Cuban government.

3. Identify the challenges faced by Cameroon in the provision of health care services.

4. Suggest measures that can be adopted by Cameroon to improve on her health care service performance.

5. Explore the Cuban approach that can be adapted in the Cameroon system.

This work therefore answers the following research questions:

1. Why does Cuba an underdeveloped country render one of the best health care services in the world?

2. What educational strategies are put in place to achieve this?

3. Why Cameroon is unable to render excellent health services like Cuba?

4. What strategies can be put in place to improve Cameroon's situation?

5. Can Cameroon draw inspiration from the Cuban strategy?

\section{Methodology:}

The historical and causal comparative approach is employed here. Comprehensive studies of the Cuban and Cameroon education and health care systems have been studied through the use of documents and the following analysis presents to us the reasons why Cuban health care is the best and the plan put in place for this to be realised. It also presents the reasons why the nation Cameroon can't produce a good health care service despite the availability of natural resources.

\section{Conceptual/Literature Review}

\section{Contextualising Cubans educational successes}

The Cuban educational system has long enjoyed a reputation for high quality Recent studies comparing achievement tests scores from Cuba with those from other Latin American countries, have further highlighted the achievements of the Cuban system. Figure 1 provides illustrative comparisons, in which Cuban students score significantly higher than do students in other Latin American countries, often by as much as two standard deviations. The Cuban education system has performed most satisfactorily on other conventional measures as well 2 According to official data, for example, 98 per cent of Cuban children of the appropriate age attended preschool in 1997-98. The enrolment rate for 6 to 16 -year olds was 94.2 per cent, and primary school gross enrolment exceeded 100 per cent. Repetition rates were 1.9 per cent in primary school, 2.8 per cent in secondary and 1.8 per cent in pre-university school. Age-grade distortion was about 2.5 per cent in primary, 3.7 per cent in basic secondary and 0.9 per cent in preuniversity. In the mid-1990s there were 241,000 illiterates, out of a population of 11 million. In 1959, in stark comparison, half of Cuba's children did not attend school at all, 72 per cent of 13 to 19 year olds failed to reach intermediate levels of schooling, and there were over one million illiterates. Cuba's schools have been remarkably successful in achieving gender equity, reaching rural and disadvantaged populations, and fostering community participation, even in the context of rapidly dwindling resources. Cuba is a poor country, and the past decade has been particularly difficult economically. Yet the success of its schools flaunts conventional wisdom: Education in Cuba is entirely public, centrally planned, and free, in a global reform environment of privatization, downscaling of the state role, and cost recovery. The Cuban education system is characterized by:

Sustained and high levels of investment in education

Consistent policy environment and political will in support of education for all

Quality basic education, including early childhood and student health initiatives, literacy, adult and non-formal education programs

Universal access to primary and secondary school

Complementary educational support systems: early childhood and student health, literacy, adult and non-formal education

$>$ Highly professional, well-trained teachers of high status

$>$ On-going professional development of teachers

$>$ Low-cost instructional materials of high quality

$>$ Creativity on the part of local educators in adapting and developing instructional materials

System-wide evaluation

$>$ Solidarity within schools and classrooms; competition among schools and classrooms

Significant community participation in school management 
$>$ Compensatory schemes for disadvantaged and rural children

$>$ Clear connections between school and work: and

$>$ An emphasis on education for social cohesion.

\section{Sustained Investments in Education}

\section{High Levels of Investment}

Cuba devotes about 10 to 11 per cent of its GDP to education, a very high percentage compared with the rest of the region or with the 6 per cent recommended as adequate by UNESCO. Of course, the size of GDP allocated to education alone is insufficient to define an effective education system.

\section{High Levels of Non-salary Expenditures}

Cuba has invested substantial resources in non-salary items. Until March 1999, 60 per cent of the Education budget was devoted to teachers' salaries with the remaining 40 per cent for non-salary items used to support instruction. Both of these policies correspond to current understandings of best practices in education finance. Unfortunately, it will be difficult to maintain such a high percentage of expenditures on no salary items. In March 1999, teachers received a 30 per cent salary increase, a move that decreases the resources available for non-salary costs. Teacher motivation and retention are also threatened by decreases in the purchasing power of salaries and the attractiveness of new professional activities, especially in tourism and in foreign firms, as evidenced by teacher attrition of 4 to 8 percent per year in the eastern oriental provinces, where tourism is more developed.

\section{Sustained and Coordinated Investments}

Investments in education need to be sustained over a long period to achieve maximum results. Greater investments or allocation of resources to education as an isolated strategy do not necessarily bring better educational results

\section{Consistent Policy Environment, Supportive of Quality Basic Education}

As in many other socialist countries, the MarxistLeninist philosophy of praxis inspires the objectives of the education system of educating a "New Human Being," to: assume its most basic social duties, to educate this being to produce material and spirituals goods that will serve society in a way that every human being participates in material production, in order to eliminate the contradiction among school and society, producer and consumers, intellectual work and physical work, and among cities and rural areas

\section{Clear Objectives}

The same party that has run the country for almost 40 years set these objectives, of course. Continuity of educational policy and strategy-quite unusual in most countries of the region-has contributed to the achievement of goals set by party and government. The different components of the education system are articulated around common objectives, subject to constant evaluation with the participation of the broader educational community, and cantered in the classroom

\section{Stability}

In many Latin American countries, frequent political changes may impede the development and consolidation af educational strategies and achievements. The Cuban experience suggests that measures are needed to protect the education system from the disruptive effects of continuous changes in strategies and plans. Education is a long-term investment requiring consistent policies and political stability to grow. This stability, however, was achieved at the cost of one-party rule.

\section{Access to Quality Basic Education}

The great emphasis placed on education and the high degree of collective control ensure that access to education is effectively universal. The high levels of investment permitted an emphasis on both equity and quality. Comprehensively childhood and student health services, widespread literacy, adult, and nonformal education programs support the objectives of basic education for all.

\section{Professional High-status Teachers and Ongoing Professional Development Lifelong Training}

Teacher training is a lifelong process including training on the job as well as formal and informal training. Its major aim is to support teachers to improve classroom practice. Fifteen higher education pedagogical institutes (HPI, institutospedagogicos supeniores) and the pedagogical faculties provide 
formal preparation of teachers for day-care centers, primary schools, and intermediate schools. HPIs offer formal daytime courses for pre-university graduates and mid-level graduates of technical and vocational schools. Preservice courses consist of five years of training, while in-service courses last six years. Training for school directors is provided at the same time as teacher training, so that directors will understand the teacher development process.

\section{School-based}

Pre- and in-service teacher preparation emphasizes basic knowledge, skills, values and attitudes. There is a balance of didactics, pedagogy and subject matter knowledge. A strong linkage between theory and practice characterizes teachers' professional development during both pre- and in-service teacher phases. Both pre- and in-service teacher training are school based, to foster greater relevance of teacher training to school and student needs and to link training institutions and schools. To reduce the distance between academic teacher training and schools, a teacher trainer candidate must complete as a prerequisite a significant number of years (usually 6 to 7) as a teacher at the level at which he or she intends to prepare teachers.

\section{Community of Learning}

Teacher's Strong emphasis is given to teamwork and exchanges of experience. Each area $N$ has acolectivopedagogico for each discipline (ciencias naturales, ciencias sociales, etc.). These co/ectivo pedagogico meet periodically to discuss teaching methods, produce learning materials, adapt curricula to local needs, and exchange experiences. The colectivopedagogico develops a "bank of problems" (banco de problemas) and develops plans to address these problems. Every program has a methodological guidebook for teachers of each grade that provides examples of good lessons and guidance on how to teach different learning units. The colectivo of teachers meets every two weeks to discuss teaching strategies, the problems of the school, evaluation, and the general educational "climate" of the school. Institutional support is provided to schools to promote professional development among teachers. A metodologo works with teachers to supporthem in different subjects. Such approaches to ongoing professional development are consistent with the best current thinking in education internationally

\section{Action Research}

Every teacher is expected to carry out applied research on ways to improve learning achievement and systematize pedagogical experience. During training, teachers are prepared to carry out classroom studies on how to address student problems. Every two years teachers presentheir best work on innovative teaching practices to a "municipal education conference" (pedagogia). Municipalities select the best research for the provincial conference, and the province selects the best for a national conference where the best 900 research projects are presented to an audience of national and international participants.

\section{Links to the Community}

Teachers interact regularly with community members and parents through mass organizations and other participatory modalities (parents' councils, parents' schools). Such interactions allow teachers to learn about local communities, and the conditions facing children and their families. This enables teachers to create a broad collaborative environment supportive of education. In this way, school-based innovations seem to last because they are supported by several actors (teachers colectivo, students, parents, community) rather than a single individual, however talented. Teachers act as community activists and are involved in activities such as parents' education and similar activities that have a positive impact on children's education. Teachers help plan school life. They spend about 80 percent of their time with students at school and the rest of their time in student's homes. According to the principle that "education is a shared responsibility," students meet to study together, from one to three times a week, in "study homes" (casas de estudio). Teachers visit parents and identify families with potential problems as well as families able to host a group of students.

\section{Evaluation and Accountability}

Continuous evaluation is considered a part of teachers' professional development, providing useful information to improve teaching practice through action research and life-long learning. Continuous assessment of teachers is a participatory process that includes all the major actors of the education process and the "teacher working group" (colectivo). Teacher 
evaluations provide recommendations for teachers' self-development plans (plan de superaci6n autodidacta o postgraduada) for the following academic year The university also participates in the evaluation of teacher performance, and by doing so receives feedback on its activities, enabling it to adapt its offerings to the realities of schools. Teacher accountability is a reality in Cuba. Inspection is not an autonomous function; career growth depends primarily on positive evaluations of teachers' classroom practice. Teacher salaries are often related to student performance. Teachers whose students fail to perform at the norm risk cuts in pay,

Cuba's literary campaign

Cuba's literacy rate is said to be one of the highest in the world.
Her literacy rate is $99.8 \%$ and is among the highest in the world higher than that of both Britain and the US. The Cuban Revolution has placed a very strong emphasis on literacy, considering it an essential component of empowering the population. Just two years after the seizure of power in 1959, the Cuban government embarked upon one of the most ambitious and wide-ranging literacy campaigns in history, sending tens of thousands of students to the countryside to form literacy brigades. Within a year, the literacy rate was increased from $70 \%$ to $96 \%$. Additionally, over the past 50 years, thousands of Cuban literacy teachers have volunteered in countries around the world including Haiti and remote indigenous communities in Australia.(Julia, Nelson and David, 2013)

According to UNESCO institute of Statistics, the literacy rates of some countries compared with that of Cuba are as follows:

\begin{tabular}{|c|c|c|c|c|}
\hline Country & $\begin{array}{c}\text { Literacy Rate } \\
\text { In } \%\end{array}$ & $\begin{array}{c}\text { Male Literacy } \\
\text { In } \%\end{array}$ & $\begin{array}{c}\text { Female } \\
\text { Literacy In \% }\end{array}$ & $\begin{array}{c}\text { Gender } \\
\text { Difference In } \\
\%\end{array}$ \\
\hline Argentina & 98.1 & Ealum 98.0 & 98.01 & -0.1 \\
\hline Cameroon & 75 & relonme 81 & 68.9 & 12.3 \\
\hline Cuba & 99.7 & $\begin{array}{l}119.7 \\
\end{array}$ & 99.8 & -0.1 \\
\hline USA & 97 & & 0. & \\
\hline United kingdom & $\begin{array}{l}0.99 \\
\end{array}$ & $2450=0499$ & $\begin{array}{r}\quad 99 \\
\end{array}$ & \\
\hline Haiti & 60.7 & 64.3 & 57.3 & 7.0 \\
\hline Nigeria & 59.6 & 69.2 & 49.7 & 19.5 \\
\hline South Africa & 94.3 & 95.5 & 93.1 & 2.4 \\
\hline Brazil & 92.6 & 92.2 & 92.5 & -0.7 \\
\hline Russia & 99.7 & 99.7 & 99.7 & 0.0 \\
\hline
\end{tabular}

Source: UNESCO Institute of statistics, 2015.

\section{In addition, Cuban health-care is free, universal,} and of high quality.

It is a small, poor island that does not exploit other countries and which suffers from a suffocating economic blockade, yet Cuba "boasts better health indicators than its exponentially richer neighbour 90 miles across the Florida straits."(USA) Life expectancy is an impressive 79. Infant mortality is 4.83 deaths per 1,000 live births compared (Carlos M., 2013). Cuba has the lowest HIV prevalence rate in the Americas. There is one doctor for every 220 people in Cuba - "one of the highest ratios in the world, compared with one for every 370 in England." Healthcare is community-based, prevention-oriented, holistic, and free. As Kofi Annan said: "Cuba demonstrates how much nations can do with the resources they have if they focus on the right priorities which are health, education, and literacy".

In addition, education is free, universal, and of high quality. 
If you want to understand the true nature of a society, then a study of its education system is a good place to start. In Cuba, high quality education at every level is regarded as a human right, and has been the major priority of the government from 1959 onwards. The result is that a poor, underdeveloped country with widespread illiteracy and ignorance has become one of the most educated nations in the world. (Incidentally, you might think that a 'dictatorship' obsessed with preserving its grip on power - as the Cuban government is portrayed in the imperialist world - would worry about the consequences of creating generations of skilled critical thinkers).

Nina Lakhani (2010) propagates that "Education at every level is free, and standards are high. The primary-school curriculum includes dance and gardening, lessons on health and hygiene, and, naturally, revolutionary history. Children are expected to help each other so that no one in the class lags too far behind. In addition, parents must work closely with teachers as part of every child's education and social development. There is a strict maximum of 25 children per primary-school class, many of which have as few as 20. Secondary schools are striving towards only 15 pupils per class - less than half the UK norm.

School meals and uniforms are free, 'Mobile teachers' are deployed to homes if children are unable to come to school because of sickness or disability. Adult education at all levels, from Open University-type degrees to English- and French-language classes on TV, is free and popular." The quality of Cuba's education is recognised at the top international levels; for example, Cuba is ranked at number 16 in UNESCO's Education for All Development Index, higher than any other country in Latin America and the Caribbean and higher than the US, which is ranked at number 25. (Nina Lakhani, 2010)

\section{More to this, the legacy of racism is being wiped out.}

Pre-revolutionary Cuba was, in effect, an apartheid society. There was widespread segregation and discrimination. Afro-Cubans were restricted to the worst jobs, the worst housing, and the worst education. They suffered from differential access to parks, restaurants and beaches. The revolution quickly started attacking racism at its roots, vowing to "straighten out what history had twisted." In March 1959 , just a couple of months after the capture of power, Fidel discussed the complex problem of racism in several speeches at mass rallies. The commitment to defeating racism has brought about tremendous gains in equality and racial integration. Isaac Saney writes: "It can be argued that Cuba has done more than any other country to dismantle institutionalised racism and generate racial harmony." Of course, deeply ingrained prejudices and inequalities cannot be eliminated overnight, and problems remain, especially as a result of the 'special period' in which Cuba has had to open itself up to tourism and some limited foreign investment. Racism thrives on inequality. However, Cuba remains a shining light in terms of its commitment to racial equality. (Isaac Saney, 2004)

\section{Gender justice is an authentic reason for medical advancement in Cuba.}

Cuba has, over the last 20 years, been making dramatic progress towards full equality for all, regardless of sexual preference. David Duran, CubanAmerican journalist promulgates that Cuba is leading by example and positively affecting the lives of not only the LGBT (Lesbian, Gay, Bisexual and Transgender) people who reside there but others all over the world. Cuba has an excellent record in terms of building gender equality. Its commitment to a nonsexist society is reflected in the fact that $43 \%$ of parliament members are female (ranking fourth in the world after Rwanda, Sweden and South Africa). 64\% of university places are occupied by women. "Cuban women comprise $66 \%$ of all technicians and professionals in the country's middle and higher levels." Women are given 18 weeks' maternity leave on full pay, with extended leave at $60 \%$ pay until the child is one year old. A recent report by the US-based Center for Democracy in the Americas noted: "By several measures, Cuba has achieved a high standard of gender equality, despite the country's reputation for machismo, a Latin American variant of sexism. Save the Children ranks Cuba first among developing countries for the wellbeing of mothers and children, the report points out. (Report by the USbased Center for Democracy in the Americas, 2012) The World Economic Forum places Cuba 20th out of 153 countries in health, literacy, economic status and political participation of women ahead of all countries in Latin America except Trinidad and Tobago.”(World Economic Forum: GCR 2014-2015) 


\section{High community spirits still exist in Cuba.}

Modern capitalism breaks down communities. Consumerism and individualism create isolation and depression. Poverty creates stress and family tension. Inequality leads to crime, which leads to a culture of fear - something that is completely inimical to the project developing a sense of community and togetherness. Cuba is said to provide a very different example. It is reported that Cuba is an exceptionally safe country, with very little in the way of violent crime. Assata Shakur advocates that Cuba enjoys a high level of participation in local administration, social stability, social welfare, low unemployment and a media that promotes unity rather than disunity. (Carlos M. 2013)

Carlos continues to explain that Cuba has excellent, mutually supportive relations with many African states. One way it provides support is by offering thousands of fully subsidised places at its universities (for example, there are 1,200 South Africans currently studying medicines in Cuba). Cuba is very active in the fight against the scourge of AIDS internationally, for example having helped Zambia to start.

\section{Cuba makes an important contribution to science.}

At the time of the revolution, Cuba was stuck in a vicious cycle of underdevelopment, without the knowledge, resources or political will to use science as a tool to improve the lives of its people. Now there are over 230 institutions devoted to scientific research and innovation. Cuba's biotech industry is considered the best in the world among developing countries, and has generated important innovations in cancer research and AIDS research. According to Carlos, Cuba created the world's first vaccine against meningitis B and Nobel Prize-winning scientist Peter Agre stated that "what this small country has done in the progress of science and eradication of diseases is worthy of recognition," adding that Cuban science's greatest asset is its large pool of highly qualified, enthusiastic young scientists. (Carlos M. 2013)

Most important of all is the fact that free medical training is given to thousands of international students.
Cuba provides full free medical training (including food and board) for hundreds of students from across the world, with a special emphasis on Africa, the Caribbean and Latin America. With over 10,000 current students, la Escuela Latinoamericana de Medicina may well be the largest medical school in the world. The quality of the training is world class and the school is fully accredited by the Medical Board of California, which has the strictest US standards. The only contractual obligation for students is that, having completed their training, they return to their communities and use their skills to serve the people. Another demonstration is that socialism implies a level of humanity, compassion and altruism with which capitalism simply cannot compete.

Poverty is becoming a thing of the past. Cuba's achievements in wiping out poverty are spectacular. Income disparity is exceptionally low. No Cuban starves; no Cuban is homeless; no Cuban is deprived of education, healthcare or housing. There are very few countries in the world that show such unambiguous dedication to people's basic human rights.

\section{THEORETICAL FRAMEWORK OF THE STUDY}

\section{Theories of Educational System Planning}

In this section, the importance of educational system planning as well as theories propounded by various educational system planning theorists will be dealt with. These theories was discussed. According to Ruperti (1979) the educational system planners should understand and sympathise with their cul= tural group, people or nation. They should also know the aspirations of the people they are planning for. It there $=$ fore makes sense that educational system planners who do not identify themselves with the nation cannot normatively plan for that nation. It is important to note that education and educational systems have always been planned but the professional educational planner is a new $=$ comer to the field of educational administration (Ruperti, 1979). The educational system planner should be a person who knows and understands the following: the $\mathrm{re}=$ ligious ground motif of the people, the number and dis= tribution of the population, the economic strength of the country, the climate of the country, the culture and the history of the people, the language and the religion of the people he is planning for. Put differently, he must ideally be part of that nation. 


\section{The Necessities of Education System Planning}

Planning a system of education is not something to be regarded as a mere academic exercise. This venture must therefore be regarded as an act of intention. Educational system planning is based on scientific research. The following are the necessities of educational system planning.

\section{Giving education cultural foundations}

With the understanding and knowledge of the culture, religion and above all the spiritual force of the people the educational system planner can effectively base his recommendations on the culture of the people he is planning for. The system of education based on the culture of the people will be most normative because it will in no small measure be part of the community life. It is practically anti-normative to impose a foreign system of education on to other nations (Barnard and Vos, 1980). The reader should understand that in recommending that education must be based on culture of the group, the importance of integration and differentiation has not been overlooked. Therefore, the culture of the group one is planning for must be taken as a point of departure in planning for that group or nation.

\section{Pointing a direction of education}

Educational systems must have short-term, medium term and long-term objectives \{UNESCO, 1969). In well-researched systems of education, these objectives will be well defined. In this manner/educational system planning will start at some point and progress towards the long-term objective. Where there is no proper planning, long-term objectives will be attempted before short-term objectives and that will result in inefficiency of the system of education.

\section{Giving education scientific foundations}

One of the prerequisites of educational system planning is scientific research. It therefore makes sense that an educational system, which has been the result of intensive research, will have scientific foundations. A system of education, which is not based on research, will degenerate into mere emotional statements of those in authority. For the educational system to be productive and economic, education will have to be based on research. This research must be continuing all the time. It should be an ongoing process (Ruperti, 1976).

\section{Vermaak's Contribution to Educational System Planning}

\section{Problems Of Educational System Planning}

Vermaak (1974) lists the following as problems regarding educational system planning:

$>$ Inequality in the educational system in respect of the expansion of primary, secondary and higher education.

$>$ Demand of teachers is too big for the existing facilities, too many children and too little accommodation.

Expenditure rises faster than income.

Non-financial bottlenecks e.g. too long periods of training the personnel for schools, and limited administrative powers.

Not enough jobs for all who have received education.

Wrong type of education for types of jobs, which exist in their world.

No correlation between general national aims and general education aims, not to mention normative educational objectives.

Political influences on educational systems. It has been pointed out that even while better planning will not easily solve these problems, planning will at least contribute to the easing of the problem.

\section{Theory and methods of educational system planning}

Education must of necessity have long-term, medium term and short-term facets. Education planning per se does not lay down the country's education policy and does not even take decision on that. It is, of course, an integral part of the administration of education and must naturally communicate with the process of decision formulation and the execution thereof. It helps those who should take decisions to be more enlightened and to analyse the specific objectives much more clearly (Vermaak, 1974).

The following are questions on educational system planning for which answers should be sought (Vermaak, 1974).

$>$ the ground motif and the accompanying factors which influence the educational system 
International Journal of Trend in Scientific Research and Development (IJTSRD) ISSN: 2456-6470

$>$ priority objectives and functions of a particular educational system and of every subsection of the educational system

different alternative methods to attain these objectives and functions

$>$ What part of the country $1 \mathrm{~s}$ resources will be devoted to education at the expense of national matters

$>$ How the financial burden in respect of education should be divided; and

$>$ How the total sources, which have been made available to education, should be distributed.

These problems, referred to above, are approached differently by education planners, especially those in the developing countries. The educational literature on educational system planning methods distinguishes between approaches: social demand approach; manpower approach, and cost benefit approach (Vermaak, 1974).

\section{The Cameroon's educational system}

Cameroon is a central African country that has set its sights on becoming an emerging economy by 2035. In order to accomplish this plan, it will have to prioritize health care access for the poorest segments of the population if it is to make solid progress toward lasting growth. The nation lacks in several domains with the health sector being the most affected. A number of reasons are responsible for the low development rate in this sector.

Primary education in Cameroon is compulsory and in the year 2000 was decree free. But this can't be compared to the completely free education in Cuba. In Cameroon, parents are still expected to pay tuition fee, buy uniforms and books. Besides, mission, private and Islamic schools are not free and so dropout rate is still high. The high level of poverty and high rate of unemployment of school products again make things complicated.

Again, some school teachers do not have professional qualification and there is a serious shortage of trained teachers in schools especially in rural areas. Though the government has intensified the training of professional teachers, they are still inadequate in meeting the current need of the school population explosion in the country. Stagnation is also caused by poor communication, social, professional, study and reading skills at the elementary level, all due to the duration and quality of training.

Resources needed for quality training are not available like relevant textbooks and at times some available ones are not contextualised, are foreign and not adapted to the Cameroonian system. These possess a serious drawback in the Cameroonian system of education as all the levels are affected by this. A situation considered history in Cuba.

The problem of overcrowded classrooms can't be left out. Classrooms in both the primary, secondary and tertiary sectors are all stuffed with above 150 students in classrooms and far more in the universities. Even though the Minister for Secondary Education in Cameroon has moved the number from 60 to 80 students per class, the number remains alarming and mere paper work. This large classroom sizes brings the student to teacher ratio at 46 per thousand at primary level, 22 per thousand at secondary level and in the various universities ratios registered after the reforms were as follows: University of Buea 1/34, University of Douala 1/45, University of Dschang $1 / 19$, University of Ngaoundere $1 / 15$, and University of Yaoundé Two 1/29, still higher than that of Cuba.( ADEA/WGHE, 1999)

The nation lacks properly trained medical doctors. The up-to-recently sole medical school in Cameroon, CUSS of Yaoundé I university, that trains and graduates Cameroonian medical doctors admits only 85 students per year, up from 45 , from the over 1,500 qualified applicants sitting for the competitive entrance examination. This low intake in CUSS as well as other medical schools in Cameroon affects the number of doctors trained generally. This has caused the doctor to patient ratio to stands at 1 - to -over 10000 in the major cities and 1 - to-over 40000 in the rural areas.

Adequate funding is lacking, with around $6 \%$ of government expenditure spent on health. To improve the availability of services and drugs, a fee-based system was introduced. This allows medical facilities to charge fees for services and treatments. Contrary to Cuba with totally free medical care for all. Whatever their social conditions, Cameroonians pay a high price for care that is often deficient and the country has no risk-sharing mechanisms such as health insurance, a situation that perpetuates the cycle of poverty. 
The Cameroon medical field experiences a severe lack of incentives to stimulate the private Sector. The taxation system in Cameroon has been blamed by many as the reason for the lack of initiatives on the part of the private sector to invest in Cameroon healthcare. This impedes private training and consequently reduces the number of medical practitioners in the country.

The involvement of three ministries namely: the ministries in charge of Public Service and Administrative Reforms (MINFOPRA), the ministry of finance (MINEFI) and the Ministry of Public Health (MINSANTE) for the integration of physicians as civil servant makes the whole integration process complex and confusing (Ngufor, 1999) for a new medical graduate. The procedure to be followed by MINFOPRA, which enables the handling of files to determine qualification and integration of medical doctors (MDs) is complex. These bureaucracies are cumbersome and unnecessarily stressful for the medical personnel and as such opens doors for brain drain. Low Salaries as well is another factor that contributes to brain drain.

The lack of continuous medical education among Cameroon medical doctors reduces medical proficiency given that there is continuous innovation and improvement in medical technology. This places them at a disadvantaged position as compared to medical doctors in Cuba who are subjected to regular and continuous training.

The Cameroon medical field is seriously handicapped by a lack of specialised medical doctors. This is because about $60 \%$ of medical doctors in Cameroon are general practitioners with less than $40 \%$ having received specialised training in health areas like gynaecology, dentistry, ophthalmology and others. This thus make the Cameroonian medical doctors lacking as compared to those in Cuba who are highly specialised.

The government policy of regional balance which is highly practiced in the recruitment of personnel in the different government training institutions may be successful in other sectors like teacher training but is very disastrous in medical training. Given that highly qualified persons for medical training in certain regions of the country are often neglected in favour of less qualified candidate from favoured regions in the name of regional balance. This is an indication that the training centres will graduate half-baked and less proficient medical doctors.

The Cameroon education system concentrates on the creation of schools without adequate facilities or resources. This is also serious drawback in the medical field. Most of the schools operate the science section but lack well equipped laboratories. As such the medical field is relatively backward in research contrary to Cuba with hundreds of research centres that enable them produce treatment for several killer diseases. In Cameroon, epidemic diseases like cholera, measles, chicken pox and others are yet to be handled by our medical researchers. Such wide spread diseases are all absent in Cuba.

\section{Study implications to educational administrators} and planners.

Based on the above systematic analysis of Cuban and Cameroon educational systems of education, it is imperative to draw certain implications or lessons learned from Cuba's strides so that Cameroon can reorganise her educational setting to promote quality healthcare services. This section identifies five quality indicators of effective policy development and implementation. These quality indicators which emerged from this study are consistent with the evidence-based principles needed for a more sustainable Africa.

\section{Practice-Policy Alignment}

Effective practices are more feasible when policy supports their implementation. Conversely, when policy and evidence-based practices are not well aligned in Cameroon, policy can act as a barrier to achieving expected student outcomes. For example, consider the following scenario: Peer coaching among teachers is one of a district's evidence-based professional development practices for improving student academic achievement. This practice involves teachers making multiple visits to other teachers' classrooms and debriefing sessions after each visit. However, district policy states a teacher may be out of the classroom for professional development only one day per semester. This district policy creates a barrier to peer coaching which could be solved by a revision that allows teachers more time away from their classrooms for coaching activities. Aligning policy with evidence-based practices requires asking the question, "Will changing a policy improve student 
outcomes?" If the answer is yes, then school and educational administrators, policy makers, parents, community members, and other stakeholders can use this as an opportunity to work together on change.

\section{Stakeholder Engagement}

States and districts build community support for education policies (e.g., state standards, comprehensive practices, funding) by engaging parents, business leaders, and other stakeholders early in the process. To achieve full collaboration, active stakeholders should represent all community members invested and interested in the successful outcomes of students in the district. This approach requires that district leaders think expansively about who their stakeholders are, such as families, teachers, students, business leaders, local child-serving organizations, and others. This paper offers valuable tools for making sustainable engagement happen.

\section{Active Implementation}

Active implementation is a process that involves active communication among state, district, and school leaders, soliciting input from stakeholders, and gathering relevant data. Policy alignment is one component of this process. For example, educational administrators may start by examining the degree to which a particular policy meets their district's needs. Furthermore, it is helpful to assess feasibility of existing policies, identify barriers to implementation, and determine the sources of those barriers. Following this process helps to identify needed policy changes.

Once a team determines to change a policy, leaders and stakeholders begin practical preparations to make the change. They will often conduct a thorough review of documents, confirm and clarify barriers, establish individual and procedural authority for decision-making, and create multi-dimensional communication protocols with stakeholders. This stage can also involve significant training and coaching for those involved in the implementation of a new policy. Inevitably, when a new policy takes effect, challenges emerge. During this time, a district leadership team may develop and use strategies to promote continuous improvement and rapid-cycle problem solving based upon data. When the team confirms policy barriers, they identify short-term work-around and long-term solutions. This phase focuses on creative problem solving in the short term, while in a parallel process, state and district leaders create strategies to achieve long-term solutions. After implementing policy changes, leaders should engage in on-going evaluation and provide required support to ensure that new policies are achieving desired outcomes.

\section{On-going Evaluation and Support}

As teachers and staff work to implement new policy supported practices, they may experience barriers. The implementation literature suggests that improvement cycle helps to evaluate effectiveness of new practices and identify needed supports.

Such improvement cycles allow for testing if new policy and practice serves the desired function and are implemented as intended (form and function).

\section{Transparency}

A final indicator of effective policy development and alignment is transparency throughout the process. Best practices for transparency include making policy documents accessible to the public in many formats (e.g., printed, electronic/web friendly, translated into a variety of languages), understandable to all stakeholders (e.g., plain language, linguistically relevant to the community), and distributing supporting documents to specific stakeholder groups to increase understanding and buy-in.

Proposed solutions to step up the Cameroonian health care service delivery.

The Cameroonian government is taking curative measures to upgrade her heath care service, but these need to be strengthened and be as comprehensive as possible. There is also a need for innovation, as well as reason to embark on a rigorous and aggressive health technological transfer. This section proposes some solutions that, if implemented, can step up the health care situation of Cameroon. Some of these measures are;

Educational Strategies and training is the most important area to use to step up the Cameroonian health care state of affairs. An important approach to increasing the number of health workers in developing countries especially Cameroon is the "scaling up" of health professional education and training (W.H.O, 2006; Chen et al. 2004) including the establishment of in-country and regional specialist 
training (Connel, 2004). Since 2000, many schools of medicine, both public and private have been created to increase the number of health personnel in the country. During the president's address to the youths on the $10^{\text {th }}$ of February 2008, he announced that the number of medical personnel to be trained will increase from 85 to 450 per year. (Cameroon Tribune, 2008).

With decentralization in Cameroon, the creation of a medical school in each region of Cameroon may reduce the imbalance. For, Wibulpolprasert and Pengpaibon (2003), the establishment of regional medical schools is also a good measure for the equitable distribution of health care services and doctors. The opportunities for professional advancement need to be improved to reduce the number of professionals moving to other countries for reasons of furthering their studies.

Cameroon needs to strengthen basic and postgraduate training, with specialization and refresher courses within the country. Postgraduate training in all the medical fields including cardiology, neurology, neurosurgery, cardiac surgery, oncology, and nephrology should be provided to address a continuing dependence on overseas schools, as well as a failure of most overseas-trained specialists to return home.

This training should take off from basic education with effective compulsory and free education up to the tertiary level so as to improve the literacy rate as well reduce the pupil teacher and student teacher ratio.

The educational system in Cameroon should lay emphasis and focus on health care, education, literacy, training and continuous training of medical personnel in the country.

A major canker worm that has been plaguing the Cameroon health service delivery is the practice of tribalism, nepotism and favouritism in the admission of students in the various medical institutions and appointments to health institutional administrative positions. To solve this problem requires the powers that be to consider merit and place it on a high premium. This will help step up performance and effectiveness on the delivery of health services in Cameroon.

\section{Concluding}

The Cubans found a way, in their own particular environment, to apply with great success a body of knowledge generally known in other countries where application has been difficult or impossible for a variety of political, socioeconomic, and cultural reasons. If Cameroon applies many of the principles effectively demonstrated in Cuba, using mechanisms and incentives in her economy, it will induce changes and result in education and health improvement.

Cameroon policy makers will have to rethink new strategies to improve on their educational system that is result based.

\section{References}

1) ADEA/WGHE (1999). Reforming a National System of Education: The Case of Cameroon. Washington DC: ADEA/World Bank.

2) Bernard and Vos (1980). 'Functional Analysis of Educational Planning: The internal Division of Functions and Administrative organisation within the Ministry of Education, in Administrative Aspects of Educational Planning', Paris: UNESCO-IIEP.

3) Cameroon Tribune (2008). Education, ethnicity and reproductive practice in Cameroon. 58, No 2153-79

4) Carlos, M. (2013). Business Administration Model: What it is and what it is not. Entrepreneurship Journal, Vol. 174 No. 2, Wiley Online Library.

5) Connel, J.P. (2004). Relationships Matter: Linking Teacher support to students. Journal of School Health, Vol. 74 No. 7

6) Isaac, S. (2004). Cuba: A revolution in motion. The University of Michigan: Fernwood Publishers.

7) Julia, N., Nelson, S. and David, B. (2014). Socialist Ideology and the transformation of Cuban Education: New York: Oxford University Press.

8) Nina Lakhani, (2010). Education and National Development: A comparative perspective. United Kingdom: Pergamon Press.

9) Ngufor, T. (1999). The health workers crises in Cameroon. Citeeseerx.ist.psu.edu.viewdoc. 
10) Report by the US Based Conference, (2012). Condition of America's Public School Facilities: 2010-13 NCES 2014-022.

11) Ruperti, F. (1979). Educational Development. International Social Science Journal, XXIX (4), pp 628-50.

12) UNESCO (1990). Meeting Basic Learning Needs: A vision for the 1990s. Background Document, World Conference on Education For All. Jomtien, Thailand 5-9 March 1990.

13) UNESCO (1969). Economic and social aspects of educational Planning. Paris: UNESCO.

14) Vermark J. (1974). The political economy of Education, London: Donworth.

15) WHO (2006). What are the effects of education on health? OECD.org. report. Geneva, Switzerland. 